\title{
Influence of depression symptoms on serum tumor necrosis factor- $\alpha$ of patients with chronic low back pain
}

Haili Wang ${ }^{1 *}$, Carsten Ahrens ${ }^{1}$, Winfried Rief ${ }^{2}$, Simone Gantz ${ }^{1}$, Marcus Schiltenwolf ${ }^{1}$, Wiltrud Richter ${ }^{1}$

\begin{abstract}
Introduction: Patients with chronic low back pain (CLBP) have high rates of comorbid psychiatric disorders, mainly depression. Recent evidence suggests that depressive symptoms and pain, as interacting factors, have an effect on the circulating levels of inflammatory markers relevant to coronary artery disease. Our previous work showed a higher serum level of an inflammatory marker tumour necrosis factor-alpha (TNF $\alpha$ ) in patients with CLBP, which did not correlate with intensity of low back pain alone. In the present study we investigated the cross-sectional associations of depressive symptoms, low back pain and their interaction with circulating levels of TNF $\alpha$.

Methods: Each group of 29 patients with CLBP alone or with both CLBP and depression was age-matched and sex-matched with 29 healthy controls. All subjects underwent a blood draw for the assessment of serum TNF $\alpha$ and completed a standardised questionnaire regarding medication, depression scores according to the German version of Centre for Epidemiological Studies Depression Scale (CES-D), pain intensity from a visual analogue scale, and back function using the Roland and Morris questionnaire. The correlations between TNF $\alpha$ level and these clinical parameters were analysed.

Results: There were no differences in TNF $\alpha$ level between CLBP patients with and without depression. Both CLBP patients with $($ median $=2.51 \mathrm{pg} / \mathrm{ml}, P=0.002$ ) and without (median $=2.58 \mathrm{pg} / \mathrm{ml}, P=0.004$ ) depression showed significantly higher TNF $\alpha$ serum levels than healthy controls (median $=0 \mathrm{pg} / \mathrm{ml}$ ). The pain intensity reported by both patient groups was similar, while the patients with depression had higher CES-D scores $(P<0.001)$ and worse back function $(P<0.001)$. The variance analysis showed that the interaction between TNF $\alpha$ level and pain intensity, CES-D scores, sex, body mass index and medication was statistically significant.

Conclusions: Depression as a comorbidity to CLBP did not influence the serum TNF $\alpha$ level. It seems that TNF $\alpha$ somehow acts as a mediator in both CLBP and depression, involving similar mechanisms that will be interesting to follow in further studies.
\end{abstract}

\section{Introduction}

Patients with chronic low back pain (cLBP) very often additionally present psychiatric disorders, mostly affective disturbance. The most common of these disorders is depression. Equally, depression is frequently associated with pain. Some 30 to $60 \%$ of cases of depression are accompanied by pain, and vice versa [1]. Pain is a major predictor of depression and anxiety, and depression seems to be an important predictor for work

\footnotetext{
* Correspondence: haili.wang@med.uni-heidelberg.de

'Department of Orthopaedic Surgery, University of Heidelberg, Schlierbacher Landstrasse 200a, 69118 Heidelberg, Germany

Full list of author information is available at the end of the article
}

disability of patients with chronic pain [2]. The costs of medical treatment for cLBP patients with depression was found to be 2.8 times higher than those for patients without depression [3], and the economic cost of depressive disorders is higher in the presence of coexisting pain [4]. The accompanying depression should therefore be recognised early and taken into account in the treatment strategy for chronic pain [5-8].

To date, however, pain and depression have been considered as separate entities and therefore treated in isolation; the pathophysiology of both pain and depression are not yet wholly clarified. Patients with pain or depression have often been observed to present

\section{C) Biomed Central}


common clinical features such as lethargy, anorexia [9], sleepiness [10], hyperalgesia [11], reduction in grooming [12] and failure to concentrate [13], which indicates that pain and depression may share some aspects of pathophysiology represented by common pathways and neurotransmitters.

Over the past decade, numerous studies have demonstrated that cytokines seem to play an important role in both pain and depression, respectively [14-19]. Cytokines can, however, act as a central link between pain and depression [20]. This knowledge stimulates our interest in the potential involvement of immune impairment in coexisting cLBP and depression.

Our previous work revealed elevated TNF $\alpha$ serum level in patients with cLBP, and that confounding parameters such as age, sex, body mass index, alcohol, cigarettes, pain rating and back function did not influence the TNF $\alpha$ serum level [21]. This observation prompts the question: which factors did influence the TNFa serum level?

To date, no studies have investigated the TNF $\alpha$ profile in coexisting pain and depression. In the prospective cross-sectional clinical study described here, we set out to determine whether comorbid depression might affect the TNF $\alpha$ serum level in patients with low back pain, or whether TNF $\alpha$ might regulate both pain and depression together. Our hypothesis was that patients with both cLBP and depression display higher TNF $\alpha$ serum levels than patients with cLBP alone and there are cross-sectional associations of pain, depressive symptoms and their interaction with TNF $\alpha$ in cLBP.

\section{Materials and methods Subjects}

All participants gave informed consent, and the study was approved by the local ethics committee of the University of Heidelberg, Germany. Participants were consecutively recruited from the Department of Orthopaedic Surgery of the University of Heidelberg. Each group of 29 patients with CLBP alone or with cLBP together with depression ( CLBP + DE) were matched with 29 healthy controls by age and sex.

The inclusion criterion for pain was CLBP as the main symptom, defined as disabling pain of at least 6 months' duration that led to the patient being on sick leave for at least 6 weeks. Patients with other pain locations as their main symptom and patients with multiple major pain locations were excluded from this study.

The inclusion criteria for the diagnosis of depression were: an International Statistical Classification of Diseases and Related Health Problems (10th revision) diagnosis of a current and at least moderate depressive episode; and a minimum German version of Centre for Epidemiological Studies Depression Scale (CES-D) score of 25.
Exclusion criteria in patients and controls were: tumour disease (diagnosis from history and by radiographic examination/magnetic resonance imaging (MRI)); trauma/fracture (history and radiographic examination); inflammatory systemic disease or infection - for example, spondylodiscitis (blood count and radiographic evaluation/MRI); nucleus pulposus prolapse with corresponding radicular pain (clinical examination, MRI); structural pathology of the lumbar spine - for example, spinal stenosis or spondylolisthesis (radiographic evaluation/MRI and clinical examination); rheumatological disease; serious cardiopulmonary, vascular or other internal medical conditions; any sensorimotor and/or neurological deficits in the lower extremity (clinical examination); spinal surgery in the year before admission to multidisciplinary therapy; radiographically apparent degenerative changes in the lumbar spine (grade II or above according to the Kellgren and Lawrence classification [22]); or medication that may influence the TNF $\alpha$ level (for example, oral or local corticosteroids, aspirin, nonsteroidal antiinflammatory drugs, anti-TNF $\alpha$ therapy).

\section{Evaluation}

At study entry, the initial evaluation included clinical and radiographic examination and also MRI of the lumbar spine in all patients of the entire study, and blood count in all patients and controls. Patients were evaluated by standardised questionnaires and physical examinations, including analysis of blood samples.

The average pain intensity of all patients was determined from a visual analogue scale recording from 0 (no pain) to 10 (severe pain) during the past 24 hours and the past week. Measures of pain-related disability was assessed using the Roland and Morris questionnaire [23], which is a self-administered questionnaire consisting of 24 items chosen to reflect varied activities of daily living. An item receives a score of 1 if it is checked as applicable by the respondent, and a score of 0 if it is not marked. Accordingly, total scores can vary from 0 (no disability) to 24 (severe disability).

The CES-D is a well-established self-reporting instrument to assess the level of depression, with 20 items and a potential overall score of 0 to 60 . It has high specificity (94\%) for the identification of acute depression if a score of at least 23 points is reached and the correlation coefficient to other instruments for measuring depression, such as the Hamilton Depression Scale, is acceptable $(r=0.49)$ and increases with recovery from depression $(r=0.86)$ [24]. To identify other confounding factors, at each time point the patients filled in this standardised questionnaire about depression (CES-D), sleep duration, alcohol and nicotine consumption, and exercise. To identify confounding factors of medication, the drug intake in the two 
groups was studied accordingly to the Anatomical Therapeutic Chemical Classification System.

\section{Determination of cytokine levels in serum}

At the given time points, venous blood was taken from the cubital vein between 8:00 and 9:00 am. Blood samples were centrifuged at $2,000 \mathrm{rpm}$ at $4^{\circ} \mathrm{C}$ within 30 minutes of withdrawal, and serum was stored at $-80^{\circ} \mathrm{C}$. TNF $\alpha$ serum levels were analysed in duplicate using a Bio-Plex cytokine assay (Bio-Rad Laboratories, Munich, Germany) according to the manufacturer's instructions. The median fluorescence intensity of standards and patient samples were determined. Using the Bio-Plex Manager software, serum levels of TNF $\alpha$ were deduced from the standard curve. The intra-assay coefficient of variation was 5 to $10 \%$.

\section{Statistical analysis}

The nonparametric Mann-Whitney test was used to compare groups and was adjusted with Bonferroni correction. Correlations between the individual groups and cytokines were investigated using Pearson correlation analysis. Variance analysis was used to evaluate the interaction between TNF $\alpha$ level, pain intensity and depression scores. Drug intake was analysed as captured/noncaptured without considering the dose. $P<0.05$ was considered statistically significant; $P<0.01$ was highly significant. The data were analysed using SPSS 15.0 software (SPSS, Chicago, IL, USA).

\section{Results}

TNF $\alpha$ serum levels

The circulating TNF $\alpha$ serum levels of patients with and without depressive symptoms were $2.51 \mathrm{pg} / \mathrm{ml}$ and
$2.58 \mathrm{pg} / \mathrm{ml}$ (median), respectively (Figure 1). The levels were significantly higher than those of healthy controls $(0.1 \mathrm{pg} / \mathrm{ml})(P=0.002$ for cLBP $+\mathrm{DE}, P=0.004$ for cLBP). No differences in TNF $\alpha$ levels between the cLBP + DE group and the cLBP group were seen in this study.

\section{Clinical characteristics between groups}

Table 1 presents the clinical characteristics of participants. Overall there were no statistically significant differences for age, sex, and body mass index between all three groups. The reported sleep duration, exercise level, or alcohol and nicotine consumption in the past 24 hours within the three groups were comparable $(P>0.05)$. Even the pain intensity of both patient groups did not differ from each other $(P>0.05)$. Patients with both cLBP and depressive symptoms, however, had significantly higher CES-D scores $(P<0.001)$ (Figure 1$)$ and worse back function $(P<0.001)$ than patients with cLBP alone. The medication (inclusive antidepressants) intake between the two groups was contrastable, except that patients in the cLBP + DE group were taking significantly more nonsteroidal anti-inflammatory drugs (M01A) than patients with cLBP alone at T0 $(P=0.037)$.

\section{Correlation between TNF $\alpha$ serum level and confounding factors}

In an unadjusted analysis, no correlation was found between TNF $\alpha$ serum level and age, sex, body mass index, pain intensity, CES-D score or back function. The single correlation was found between the TNFa serum level and intake of analgesics in the cLBP + DE group $(P=0.027>0.005, S=-0.411)$, however, this single correlation disappeared after assessment of all variables

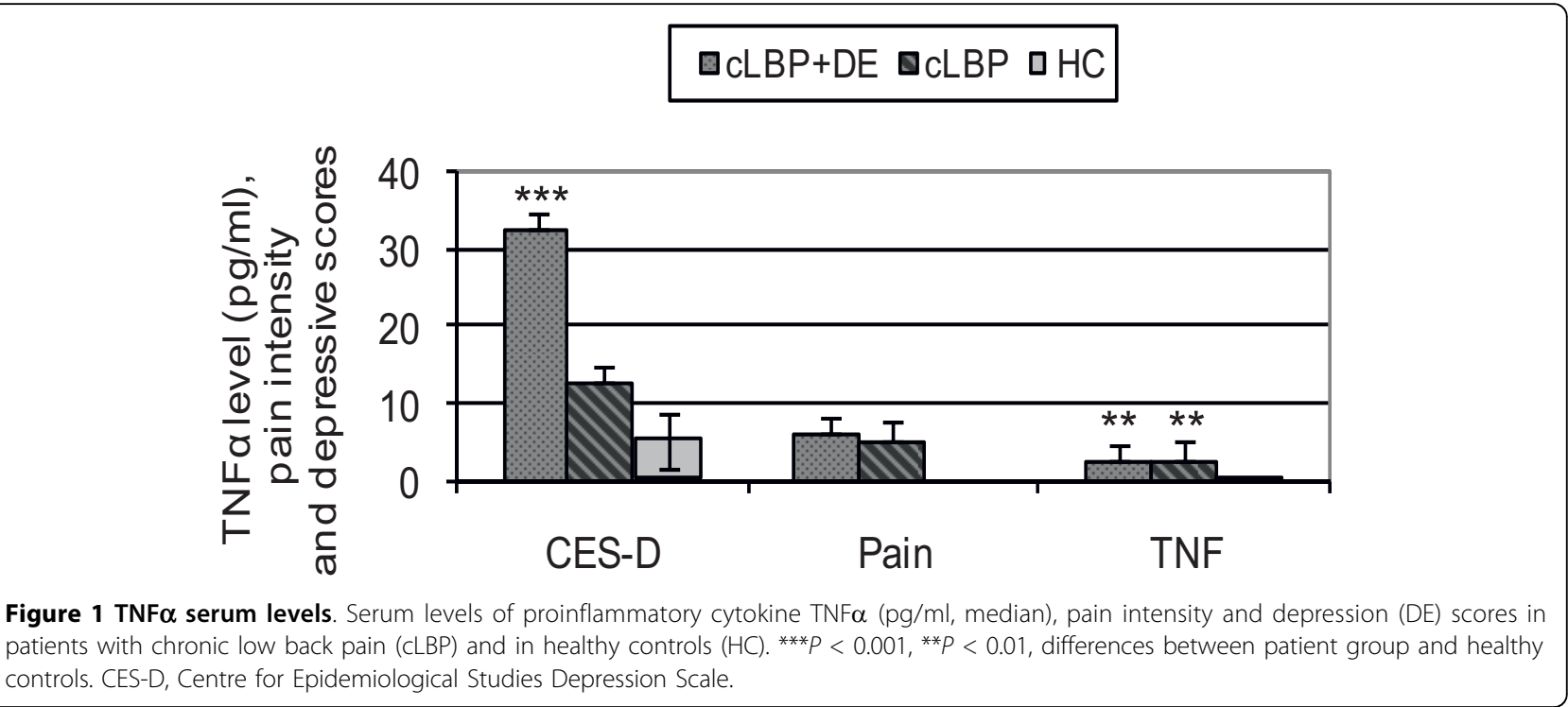


Table 1 Clinical and psychosocial data for all subjects

\begin{tabular}{|c|c|c|c|}
\hline & Healthy controls $(n=29)$ & $\begin{array}{l}\mathrm{CLBP}+\mathrm{DE} \\
(n=29)\end{array}$ & $\begin{array}{l}\text { CLBP } \\
(n=29)\end{array}$ \\
\hline Sex (female/male) & $17 / 12$ & $17 / 12$ & $17 / 12$ \\
\hline Age (years) & 40.72 (23 to 66$)$ & 45.31 (20 to 69 ) & 44.69 (24 to 68$)$ \\
\hline Body mass index $\left(\mathrm{kg} / \mathrm{m}^{2}\right)$ & 27.1 (18.7 to 47.8$)$ & 25.1 (18.9 to 37.4$)$ & 24.2 (17.7 to 33.3$)$ \\
\hline Sleep (hours) & $6.7 \pm 0.7$ & $5.6 \pm 1.7$ & $6.4 \pm 1.9$ \\
\hline Pain 24 hours $^{\mathrm{a}}$ & 0 & $6.30 \pm 1.89$ & $5.13 \pm 2.30$ \\
\hline Pain 7 days $^{a}$ & 0 & $6.29 \pm 1.58$ & $5.19 \pm 2.27$ \\
\hline CES-D score & 5 & $32.81 \pm 9.38^{*}$ & $12.68 \pm 6.64$ \\
\hline Back function (RM) & 0 & $13.77 \pm 5.26^{*}$ & $10.19 \pm 5.65$ \\
\hline Exercise in past 24 hours (hours) & $5.98 \pm 2.33$ & $5.68 \pm 5.09$ & $5.28 \pm 3.95$ \\
\hline Alcohol consumption (24 hours) & $16 \%$ & $16 \%$ & $19 \%$ \\
\hline Nicotine consumption (24 hours) & $20 \%$ & $42 \%$ & $23 \%$ \\
\hline \multicolumn{4}{|l|}{ Medication } \\
\hline Nonsteroidal anti-inflammatory drugs & 0 & $28 \% \%^{*}$ & $7 \%$ \\
\hline Opioids & 0 & $24 \%$ & $28 \%$ \\
\hline Antidepressants & 0 & $24 \%$ & $17 \%$ \\
\hline
\end{tabular}

Data presented as $n$, mean (range), mean \pm standard deviation or percentage. CLBP, chronic low back pain; DE, depression; CES-D, Centre for Epidemiological Studies Depression Scale; RM, Roland and Morris [23]. ${ }^{a}$ : Visual analogue scale, 0 to $10 .{ }^{*}: P<0.05$.

(as there were 11 variables in this study, correlation should be $P<0.05 / 11=0.005$ ).

In the variance analysis, using TNF $\alpha$ as a conditioned variable presented no significant interactions between TNF $\alpha$, pain intensity in the past 24 hours $(P=1.000)$ and CES-D scores $(P=1.000)$.

\section{Discussion}

Many separate studies have shown that the proinflammatory cytokine TNF $\alpha$ may play a role in the pathophysiology both of pain and depression. TNFa is responsible for the triggering of mechanical nociception [25], peripheral sensitisation of nociceptors [26] and central sensitisation of posterior horn neurons [27]. In a chronic constructive injury model, levels of TNF $\alpha$ and IL-6 were upregulated when the spinal nervous system was chronically injured [28-31]. Administration of TNF $\alpha$ inhibitor countered the associated pain behaviour and hyperalgesia [32,33]. The role of TNF $\alpha$ in pain was reported by many clinical studies of chronic pain [34], neuropathic pain $[35,37]$ and fibromyalgia syndrome $[38,39]$. Concerning the role of TNF $\alpha$ in depression, a lot of studies demonstrated significantly higher TNF $\alpha$ levels in major depressive disorder patients compared with normal controls $[40,44]$ and a decrease of these levels after treatment with antidepressants, then reaching similar levels to healthy controls [40].

A new observation from the current study is detection that the quantity of serum TNF $\alpha$ from patients with CLBP was not intensified with coexisting pain and depressive symptoms. Patients with both pain and depression or patients with pain alone showed no difference of circulating TNF $\alpha$ level. The interaction between
TNF $\alpha$ level and pain intensity or depression scores was not statistically significant. It seems that the TNF $\alpha$ level related to depression or to pain may be regulated by the same mechanism. There are several plausible mechanisms that could explain these results and the relationship between pain, depression and TNFa.

Stresses could be a common source of inflammatory response in the body of both pain and depressive patients. Increased sympathetic nervous system activation in response to stress has been suggested to mediate inflammatory processes [45]. Conceivably, depression has been induced in many of our patients by stress and chronic, persistent pain is the big stressor for the patients. Exposure to stressful life events such as bereavement, divorce and academic stress is reported to cause depression and impairments of cellular immune function that may affect each other [46-51]. Chronic stress impaired at least T-helper type 1 responses, including the TNF $\alpha$ response $[49,52]$. Stressful life events coincide with depressive episodes but can also activate the immune/inflammatory system, leading to excess secretion of cytokines. In addition, there are occasional reports of decreased cytokine secretion in conjunction with the administration of antidepressant medication [43,53-55].

Recent developments in neuroscience and psychoimmunology point to the coexistence of pain and depression. A newly published review pointed out that the pathophysiologies of pain and depression may overlap in many respects [56]. Several brain regions are implicated in both major depressive disorder and pain. For example, the insular cortex $[57,58]$, the prefrontal cortex $[59,60]$, the anterior cingulate cortex $[61,62]$, the 
amygdala and the hippocampus [63-65] are activated and/or altered in response to both depression and pain. Moreover, Robinson [56] verified that shared neurocircuits and neurochemicals play an important role connecting the pathophysiologies of depression and pain disorders.

This knowledge parallels our opinion. We challenge the widely held cytokine hypothesis of both CLBP and depression with the alteration of proinflammatory cytokine TNFa.

The common feature between pain and depression in relation to cytokines is the stress reaction within the hypothalamic-pituitary-adrenal (HPA) axis that exists in patients with CLBP and in those with depression. In animals, stress can activate proinflammatory pathways in the brain by activation of microglial cells [66,67]. In humans, modulation of the immune system by stress is well known [68]. Studies of chronic and acute stress in models of human stress have shown higher circulating levels of IL- 6 and TNF $\alpha$ than in controls [68-70]. In general, depressed patients have an activated HPA axis, increased levels of cortisol and increased circulating levels of several proinflammatory cytokines, which can further stimulate the HPA axis and cortisol production [71].

In individuals with depression there is evidence for malfunction of cortisol receptors leading to cytokineinduced cortisol resistance, impaired feedback inhibition of the HPA axis and sustained activation of immune cells [72,73]. Depression and psychological distress sensitise and enhance inflammatory responses to subsequent stressful events [68]. The release of proinflammatory cytokines by peripheral immune cells during inflammation, infection or trauma leads to release of proinflammatory cytokines by glia in the central nervous system; these cytokines are associated with induction and maintenance of pain [74]. Cytokines can enter the brain and cause alterations in the metabolism of serotonin and dopamine. Additionally, cytokines activate chronic renal failure, which in turn leads to an increase in serum glucocorticoid levels [75]. Under physiological conditions, increased serum glucocorticoid levels induce an inhibition of the HPA axis. After prolonged stress, this negative feedback mechanism is disrupted [56]. cLBP as a persistent stressor may possibly also interrupt the negative glucocorticoid feedback on the HPA axis.

Historically, pain and depression have been conceptualised and treated as discrete phenomena, although they are highly comorbid disorders. Our findings illustrate the importance of shared common neurochemicals (TNF $\alpha$ ) in the development of both disorders, and may provide a suggestion for the physicians - who should carefully evaluate patients presenting with either CLBP or depressive symptoms and tailor their treatment accordingly.
Potential confounding factors for the TNF $\alpha$ serum level were analysed in the present study. Age, sex, body mass index, pain intensity, CES-D score and back function did not correlate with the TNF $\alpha$ serum level individually.

\section{Conclusions}

The present study clearly shows that depression as a comorbidity did not influence the TNF $\alpha$ level in cLBP patients. In other words, a high TNFa level in patients with cLBP was not induced by accompanying depression. Our hypothesis was therefore not supported. Our previous work and the present study, taken together, confirm that there is no causal relationship between the TNF $\alpha$ serum level and CLBP, just as there is no causal relationship between cytokine alterations in the blood and depressive disorders. Rather, it seems that TNF $\alpha$ somehow acts as a mediator in both cLBP and depression, by similar mechanisms. In the further study, we followed the development both of pain intensity and depression scores parallel to the TNF $\alpha$ level in a longitudinal design of 6 months, and tried to determine the potential interaction between TNFa, pain and depression.

\section{Abbreviations}

CES-D: German version of Centre for Epidemiological Studies Depression Scale; CLBP: chronic low back pain; HPA: hypothalamic-pituitary-adrenal; IL: interleukin; MRI: magnetic resonance imaging; TNF: tumour necrosis factor.

\section{Acknowledgements}

The present work was funded by the research grant from the Orthopaedic University hospital, University of Heidelberg, Germany. The authors would like to thank Dr Dorothee Mangini-Guidano for the support of blood collection.

\section{Author details}

'Department of Orthopaedic Surgery, University of Heidelberg, Schlierbacher Landstrasse 200a, 69118 Heidelberg, Germany. ${ }^{2}$ Department of Clinical Psychology and Psychotherapy, University of Marburg, Gutenbergstrasse 18, 35032 Marburg, Germany.

\section{Authors' contributions}

HW conceived the hypothesis for the manuscript, participated in data collection, wrote the first draft of the manuscript and had primary responsibility for the manuscript process. CA participated in data collection and performed the initial statistical analyses. SG interpreted the results of statistical analysis. WR participated in the interpretation of data, and contributed to and approved the final manuscript. MS conceived the study and participated in its design and helped to draft the manuscript. WR conceived the study and supervise its design. All authors read and approved the final manuscript.

\section{Competing interests}

The authors declare that they have no competing interests.

Received: 17 November 2009 Revised: 9 April 2010

Accepted: 11 October 2010 Published: 11 October 2010

\section{References}

1. Bair MJ, Wu J, Damush TM, Sutherland JM, Kroenke K: Association of depression and anxiety alone and in combination with chronic musculoskeletal pain in primary care patients. Psychosom Med 2008, 70:890-897. 
2. Ericsson M, Poston WS, Linder J, Taylor JE, Haddock CK, Foreyt JP: Depression predicts disability in long-term chronic pain patients. Disabil Rehabil 2002, 24:334-340.

3. Sheehan DV: Establishing the real cost of depression. Manag Care 2002, 11:7-10, discussion 21-25.

4. Greenberg PE, Birnbaum HG: The economic burden of depression in the US: societal and patient perspectives. Expert Opin Pharmacother 2005, 6:369-376

5. Airaksinen $E$, Wahlin A, Larsson M, Forsell $Y$ : Cognitive and social functioning in recovery from depression: results from a populationbased three-year follow-up. J Affect Disord 2006, 96:107-110.

6. Pfingsten $M$, Schöps P: Low back pain: from symptom to chronic disease. Z Orthop Ihre Grenzgeb 2004, 142:146-152.

7. Poleshuck EL, Bair MJ, Kroenke K, Damush TM, Tu W, Wu J, Krebs EE, Giles DE: Psychosocial stress and anxiety in musculoskeletal pain patients with and without depression. Gen Hosp Psychiatry 2009, 31:116-122.

8. Schiltenwolf M: Assessment of musculoskeletal pain. Z Rheumatol 2007, 66:473-483.

9. Murray JB: Psychophysiological aspects of motion sickness. Percept Mot Skills 1997, 85:1163-1167.

10. Mullington J, Korth C, Hermann DM, Orth A, Galanos C, Holsboer F, Pollmächer T: Dose-dependent effects of endotoxin on human sleep. Am J Physiol Regul Integr Comp Physiol 2000, 278:R947-R955.

11. Maier SF, Wiertelak EP, Martin D, Watkins LR: Interleukin-1 mediates the behavioral hyperalgesia produced by lithium chloride and endotoxin Brain Res 1993, 623:321-324.

12. Dantzer R, Kelley KW: Twenty years of research on cytokine-induced sickness behavior. Brain Behav Immun 2007, 21:153-160

13. Kelley KW, Bluthé RM, Dantzer R, Zhou JH, Shen WH, Johnson RW, Broussard SR: Cytokine-induced sickness behavior. Brain Behav Immun 2003, 17(Suppl 1):S112-S118.

14. Anisman H, Hayley S, Turrin N, Merali Z: Cytokines as a stressor: implications for depressive illness. Int J Neuropsychopharmacol 2002 5:357-373.

15. Anisman H, Kokkinidis L, Merali Z: Further evidence for the depressive effects of cytokines: anhedonia and neurochemical changes. Brain Behav Immun 2002, 16:544-556.

16. Anisman H, McIntyre DC: Conceptual, spatial, and cue learning in the Morris water maze in fast or slow kindling rats: attention deficit comorbidity. J Neurosci 2002, 22:7809-7817.

17. Anisman H, Merali Z: Cytokines, stress, and depressive illness. Brain Behav Immun 2002, 16:513-524

18. Anisman H, Merali Z, Hayley S: Sensitization associated with stressors and cytokine treatments. Brain Behav Immun 2003, 17:86-93.

19. Anisman H, Merali Z: Cytokines, stress and depressive illness: brainimmune interactions. Ann Med 2003, 35:2-11.

20. Strouse TB: The relationship between cytokines and pain/depression: a review and current status. Curr Pain Headache Rep 2007, 11:98-103.

21. Wang $H$, Schiltenwolf $M$, Buchner M: The role of TNF- $a$ in patients with chronic low back pain-a prospective comparative longitudinal study. Clin J Pain 2008, 24:273-278.

22. Kellgren JH, Lawrence JS: Radiological assessment of osteo-arthrosis. Ann Rheum Dis 1957, 16:494-502.

23. Roland M, Morris R: A study of the natural history of back pain. Part I: development of a reliable and sensitive measure of disability in lowback pain. Spine (Phila Pa 1976) 1983, 8:141-144.

24. Hautzinger M, Bailer M: Allgemeine Depressionsskala. Weinheim: Beltz; 1993.

25. Cunha FQ, Poole S, Lorenzetti BB, Ferreira SH: The pivotal role of tumour necrosis factor alpha in the development of inflammatory hyperalgesia. Br J Pharmacol 1992, 107:660-664.

26. Junger $H$, Sorkin LS: Nociceptive and inflammatory effects of subcutaneous TNFa. Pain 2000, 85:145-151.

27. Cuellar JM, Montesano PX, Carstens E: Role of TNF-a in sensitization of nociceptive dorsal horn neurons induced by application of nucleus pulposus to $L 5$ dorsal root ganglion in rats. Pain 2004, 110:578-587.

28. Okamoto K, Martin DP, Schmelzer JD, Mitsui Y, Low PA: Pro- and antiinflammatory cytokine gene expression in rat sciatic nerve chronic constriction injury model of neuropathic pain. Exp Neurol 2001, 169:386-391
29. Schäfers M, Geis C, Svensson Cl, Luo ZD, Sommer C: Selective increase of tumour necrosis factor-alpha in injured and spared myelinated primary afferents after chronic constrictive injury of rat sciatic nerve. Eur $J$ Neurosci 2003, 17:791-804.

30. Schäfers M, Sorkin LS, Geis C, Shubayev VI: Spinal nerve ligation induces transient upregulation of tumor necrosis factor receptors 1 and 2 in injured and adjacent uninjured dorsal root ganglia in the rat. Neurosci Lett 2003, 347:179-182.

31. Schäfers M, Svensson Cl, Sommer C, Sorkin LS: Tumor necrosis factor-alpha induces mechanical allodynia after spinal nerve ligation by activation of p38 MAPK in primary sensory neurons. J Neurosci 2003, 23:2517-2521.

32. Sommer C, Schmidt C, George A: Hyperalgesia in experimental neuropathy is dependent on the TNF receptor 1. Exp Neurol 1998, 151:138-142.

33. Sommer C, Schäfers $M$, Marziniak M, Toyka KV: Etanercept reduces hyperalgesia in experimental painful neuropathy. J Peripher Nerv Syst 2001, 6:67-72.

34. Koch A, Zacharowski K, Boehm O, Stevens M, Lipfert P, von Giesen HJ, Wolf $A$, Freynhagen R: Nitric oxide and pro-inflammatory cytokines correlate with pain intensity in chronic pain patients. Inflamm Res 2007, 56:32-37.

35. Uçeyler N, Rogausch JP, Toyka KV, Sommer C: Differential expression of cytokines in painful and painless neuropathies. Neurology 2007, 69:42-49.

36. Uçeyler N, Eberle T, Rolke R, Birklein F, Sommer C: Differential expression patterns of cytokines in complex regional pain syndrome. Pain 2007, 132:195-205.

37. Uçeyler N, Tscharke A, Sommer C: Early cytokine expression in mouse sciatic nerve after chronic constriction nerve injury depends on calpain. Brain Behav Immun 2007, 21:553-560.

38. Wang H, Moser M, Schiltenwolf M, Buchner M: Circulating cytokine levels compared to pain in patients with fibromyalgia - a prospective longitudinal study over 6 months. J Rheumatol 2008, 35:1366-1370.

39. Wallace DJ, Linker-Israeli M, Hallegua D, Silverman S, Silver D, Weisman MH: Cytokines play an aetiopathogenetic role in fibromyalgia: a hypothesis and pilot study. Rheumatology (Oxford) 2001, 40:743-749

40. Tuglu C, Kara SH, Caliyurt O, Vardar E, Abay E: Increased serum tumo necrosis factor-alpha levels and treatment response in major depressive disorder. Psychopharmacology (Berl) 2003, 170:429-433.

41. Huang TL, Lee CT: T-helper $1 / T$-helper 2 cytokine imbalance and clinical phenotypes of acute-phase major depression. Psychiatry Clin Neurosci 2007, 61:415-420

42. Dantzer R, Wollman E, Vitkovic L, Yirmiya R: Cytokines and depression: fortuitous or causative association? Mol Psychiatry 1999, 4:328-332.

43. Dantzer R, Wollman EE, Vitkovic L, Yirmiya R: Cytokines, stress and depression. Conclusions and perspectives. In Cytokines, Stress, and Depression: Advances in Experimental Medicine and Biology. Edited by: Dantzer R, Wollman EE, Yirmiya R. New York: Kluwer Academic/Plenum; 1999:317-329.

44. Kronfol Z: Cytokine regulation in major depression. In Cytokines and Mental Health. Edited by: Kronfol Z. Boston: Kluwer Academic; 2003:259-280.

45. Suarez EC, Lewis JG, Kuhn C: The relation of aggression, hostility, and anger to lipopolysaccharide-stimulated tumor necrosis factor (TNF)alpha by blood monocytes from normal men. Brain Behav Immun 2002, 16:675-684.

46. Herbert TB, Cohen $S$ : Stress and immunity in humans: a meta-analytic review. Psychosom Med 1993, 55:364-379.

47. Herbert TB, Cohen S: Depression and immunity: a meta-analytic review. Psychol Bull 1993, 113:472-486.

48. Dunn AJ: Cytokines, stress, and depression. In Cytokines, Stress and Immunity. 2nd Edition. Edited by: Plotnikoff N. Boca Raton, FL: Taylor \& Francis/CRC Press; 2007:193-214

49. Segerstrom SC, Miller GE: Psychological stress and the human immune system: a meta-analytic study of 30 years of inquiry. Psychol Bull 2004, 130:601-630

50. Irwin M, Lacher U, Caldwell C: Depression and reduced natural killer cytotoxicity: a longitudinal study of depressed patients and control subjects. Psychol Med 1992, 22:1045-1050.

51. Beaurepaire RD: Neuroimmune mediators: are cytokines mediators of depression? In Biology of Depression, from Novel Insights to Therapeutic Strategies. Edited by: Licinio J, Wong ML. Weinheim: Wiley-VCH; 2005:557-581. 
52. Murali R, Hanson MD, Chen E: Psychological stress and its relationship to cytokines and inflammatory diseases. In Cytokines, Stress and Immunity. 2nd Edition. Edited by: Plotnikoff N. Boca Raton, FL: Taylor \& Francis/CRC Press; 2007:29-49.

53. Słuzewska A, Rybakowski JK, Laciak M, Mackiewicz A, Sobieska M, Wiktorowicz K: Interleukin-6 serum levels in depressed patients before and after treatment with fluoxetine. Ann N Y Acad Sci 1995, 762:474-476.

54. Kronfol Z: Behavioural effects of cytokines: a psychiatrist's perspective. In Cytokines, Stress and Immunity. 2nd Edition. Edited by: Plotnikoff N. Boca Raton, FL: Taylor \& Francis/CRC Press; 2007:1-16.

55. Kubera M, Symbirtsev A, Basta-Kaim A, Borycz J, Roman A, Papp M, Claesson M: Effect of chronic treatment with imipramine on interleukin 1 and interleukin 2 production by splenocytes obtained from rats subjected to a chronic mild stress model of depression. Pol J Pharmacol 1996, 48:503-506.

56. Robinson MJ, Edwards SE, lyengar S, Bymaster F, Clark M, Katon W: Depression and pain. Front Biosci 2009, 14:5031-5051.

57. Biver F, Wikler D, Lotstra F, Damhaut P, Goldman S, Mendlewicz J: Serotonin 5-HT2 receptor imaging in major depression: focal changes in orbito-insular cortex. Br J Psychiatry 1997, 171:444-448

58. Frot M, Mauguière F: Dual representation of pain in the operculo-insular cortex in humans. Brain 2003, 126:438-450.

59. Apkarian AV, Bushnell MC, Treede RD, Zubieta JK: Human brain mechanisms of pain perception and regulation in health and disease. Eur J Pain 2005, 9:463-484.

60. Mondal S, Sharma VK, Das S, Goswami U, Gandhi A: Neuro-cognitive functions in patients of major depression. Indian I Physiol Pharmacol 2007, 51:69-75.

61. Alexopoulos GS, Gunning-Dixon FM, Latoussakis V, Kanellopoulos D, Murphy CF: Anterior cingulate dysfunction in geriatric depression. Int J Geriatr Psychiatry 2008, 23:347-355.

62. Honda T, Maruta T, Takahashi K: Brain perfusion abnormality in patients with chronic pain. Keio J Med 2007, 56:48-52.

63. Bingel U, Quante M, Knab R, Bromm B, Weiller C, Büchel C: Subcortical structures involved in pain processing: evidence from single-trial fMRI. Pain 2002, 99:313-321.

64. Lange $\mathrm{JH}$ : Endotoxin as a factor for joint pain and rheumatoid arthritis. Clin Rheumatol 2004, 23:566, author reply 567.

65. MacMaster FP, El-Sheikh R, Upadhyaya AR, Nutche J, Rosenberg DR, Keshavan M: Effect of antipsychotics on pituitary gland volume in treatment-naive first-episode schizophrenia: a pilot study. Schizophr Res 2007, 92:207-210.

66. Deak T, Bellamy C, D'Agostino LG, Rosanoff M, McElderry NK, Bordner KA: Behavioral responses during the forced swim test are not affected by anti-inflammatory agents or acute illness induced by lipopolysaccharide. Behav Brain Res 2005, 160:125-134.

67. Frank MG, Baratta MV, Sprunger DB, Watkins LR, Maier SF: Microglia serve as a neuroimmune substrate for stress-induced potentiation of CNS proinflammatory cytokine responses. Brain Behav Immun 2007, 21:47-59.

68. Glaser R: Stress-associated immune dysregulation and its importance for human health: a personal history of psychoneuroimmunology. Brain Behav Immun 2005, 19:3-11.

69. Glaser R, Robles TF, Sheridan J, Malarkey WB, Kiecolt-Glaser JK: Mild depressive symptoms are associated with amplified and prolonged inflammatory responses after influenza virus vaccination in older adults. Arch Gen Psychiatry 2003, 60:1009-1014.

70. Kiecolt-Glaser JK, Loving TJ, Stowell JR, Malarkey WB, Lemeshow S, Dickinson SL, Glaser R: Hostile marital interactions, proinflammatory cytokine production, and wound healing. Arch Gen Psychiatry 2005, 62:1377-1384.

71. Irwin MR, Olmos L, Wang M, Valladares EM, Motivala SJ, Fong T, Newton T, Butch A, Olmstead R, Cole SW: Cocaine dependence and acute cocaine induce decreases of monocyte proinflammatory cytokine expression across the diurnal period: autonomic mechanisms. J Pharmacol Exp Ther 2007, 320:507-515.

72. Pace TW, Hu F, Miller AH: Cytokine-effects on glucocorticoid receptor function: relevance to glucocorticoid resistance and the pathophysiology and treatment of major depression. Brain Behav Immun 2007, 21:9-19.

73. Raison $\mathrm{CL}$, Miller $\mathrm{AH}$ : Depression in cancer: new developments regarding diagnosis and treatment. Biol Psychiatry 2003, 54:283-294.
74. Watkins $L R$, Maier SF: The pain of being sick: implications of immune-tobrain communication for understanding pain. Annu Rev Psychol 2000, 51:29-57.

75. Raison $\mathrm{CL}$, Capuron L, Miller AH: Cytokines sing the blues: inflammation and the pathogenesis of depression. Trends Immunol 2006, 27:24-31.

doi:10.1186/ar3156

Cite this article as: Wang et al:: Influence of depression symptoms on serum tumor necrosis factor- $\alpha$ of patients with chronic low back pain Arthritis Research \& Therapy 2010 12:R186.

\section{Submit your next manuscript to BioMed Central and take full advantage of:}

- Convenient online submission

- Thorough peer review

- No space constraints or color figure charges

- Immediate publication on acceptance

- Inclusion in PubMed, CAS, Scopus and Google Scholar

- Research which is freely available for redistribution
Ciomed Central 